\title{
IMPLICAÇÕES DO USO DO SOLO NA OCORRÊNCIA DE FEIÇÕES EROSIVAS EM SÃO PEDRO (SP)
}

\author{
Evandro DANIEL \\ Bianca Carvalho VIEIRA \\ Tiago Damas MARTINS
}

\section{RESUMO}

Embora a erosão seja um processo natural associada aos fatores naturais como litologia, solo, morfologia das encostas e a chuva, a ação antrópica interfere na sua dinâmica, pois práticas inadequadas de uso podem potencializar a evolução dos processos. Neste contexto, este trabalho teve como objetivo analisar as implicações do uso do solo e sua influência na gênese e distribuição das feições erosivas da bacia do córrego Espraiado, São Pedro (SP), a partir de quatro cenários: 1962, 1972, 2000 e 2020. Os mapas do uso do solo e das feições erosivas foram realizados a partir de ortofotos, trabalho de campo e por um método integrado de correlação e validação entre as feições erosivas e o uso do solo, utilizando um índice estatístico potencial de erosão. Os resultados mostraram que as classes de solo exposto e pastagens são as mais suscetíveis em todos os cenários, havendo uma redução da área total das feições erosivas a partir de 2000, devido ao aumento do percentual das classes mata, área urbana consolidada e silvicultura. Por fim, as maiores suscetibilidades das classes de solo exposto e de pasto também estão associadas às classes de curvaturas côncavas e declividade entre $20 \mathrm{e}$ $40 \%$.

Palavras-chave: Erosão; Suscetibilidade; Método estatístico; Morfometria; Análise integrada.

\section{ABSTRACT}

LAND USE IMPLICATIONS ON SOIL EROSION AT SÃO PEDRO (SP). Erosion is a process long associated with natural factors, such as lithology, soil type, slope morphology, and rainfall. The anthropogenic actions interfere with these dynamics, and the improper practices of land use may accelerate this process. In this context, this study aimed to evaluate the implications of land use and its influence on the genesis and distribution of the erosive features of the Espraiado watershed at São Pedro (SP), considering four intervals in 1962, 1972, 2000, and 2020. The land use maps and erosive features were built on orthophoto, fieldwork, and an integrated method of correlation and validation between erosive features and land use, using a potential statistical index of erosion. The results demonstrated that the classes of exposed soil and pastures are more susceptible to erosion at all times and a reduction in the total area of erosive features since 2000 , due to the increase in the forest coverage, consolidated urban area, and forestry. Finally, the greatest susceptibilities of the exposed soil and pasture classes are also associated with the classes of concave curvatures and slopes between $20 \%$ and $40 \%$.

Keywords: Erosion; Susceptibility; Statistical method; Morphometry; Integrated analysis. 


\section{INTRODUÇÃO}

A erosão é um processo que põe em risco as atividades agrícolas, se revelando como uma ameaça à subsistência humana e à civilização (TRIMBLE \& CROSSON 2000, WUEPPER et al. 2020). A perda de solo ocasiona a redução das taxas de infiltração e do armazenamento da água, o que limita a disponibilidade e a distribuição de água e nutrientes para o cultivo (CROSSON 1995, THOMAZ \& FIDALSKI 2020). Embora a erosão seja um processo natural condicionado por características litológicas, pedológicas, geomorfológicas e climatológicas, a ação antrópica tem também importância, pois práticas inadequadas de uso, manejo e tipo de ocupação do solo podem potencializar a instalação e a evolução dos processos (LOHMANN \& SANTOS 2005, MEYLES et al. 2006, BORRELLI et al. 2020). Tal situação, pode ser exemplificada pelas práticas urbanas, agrícolas e de mineração executadas de forma inadequada que desestabilizam encostas e promovem o surgimento de processos erosivos, principalmente na área urbana, onde as alterações ambientais são intensas e inerentes ao maior adensamento populacional e submete o meio físico à dinamização de processos geomorfológicos, podendo acarretar o desequilíbrio do sistema morfodinâmico (ALMEIDA FILHO et al. 2016, LEITE et al. 2016).

Intervenções antrópicas como o corte de encostas para a instalação de rodovias, uso intensivo da mecanização e desmatamento, são exemplos de atividades que podem promover o surgimento de processos erosivos (GOUDIE 2004). Tais práticas alteram a dinâmica hidrológica das encostas favorecendo fluxos superficiais durante eventos mais intensos de precipitação pluviométrica (SIDORCHUK 1999, NYSSEN et al. 2002, MEYLES et al. 2006, GUTIÉRREZ et al. 2009).

Neste sentido, muitos estudos concordam que $30 \%$ da cobertura vegetal protegem o solo contra a erosão (GOUDIE 2004), pois mantém a umidade no solo, gerando aumento na gama de condições para a estabilização da superfície e, portanto, diminuição da formação da crosta ou selagem do solo, além da redução do escoamento de alto poder erosivo (MORGAN 1995, GREENE \& HAIRSINE 2004).

COUTARD et al. (1978) e QUEIROZ NETO (1978) ressaltam que a fragilidade das formações superficiais após a eliminação da cobertura vegetal primitiva é atestada pelos inúmeros sinais de erosão hídrica. Os autores relataram a constituição basicamente desses setores de badlands e de rochas friáveis (arenito de granulação média), resultado da cobertura de colúvios arenosos pouco espessos e a proximidade da rocha à superfície, que rapidamente são saturados pela água gerando o escoamento superficial. Desta forma, este trabalho teve como objetivo analisar as implicações do uso do solo e sua influência na gênese e na distribuição das feições erosivas lineares da bacia do córrego Espraiado, São Pedro (SP) a partir de quatro cenários temporais $(1962,1972,2000$ e 2020).

\section{2 ÁREA DE ESTUDO}

A bacia do córrego Espraiado (Figura 1) possui uma área de $11,98 \mathrm{~km}^{2}$ e está localizada a nordeste do município de São Pedro (SP) com suas cabeceiras de drenagem NW-SE e seu canal principal desaguando no ribeirão Araquá, afluente do rio Piracicaba, pertencente à unidade de gerenciamento de recursos hídricos do PCJ (Piracicaba/ Capivari/Jundiaí). O município está inserido na classe de alta suscetibilidade erosiva (KERTZMAN et al. 1995), o que justifica a existência de inúmeros trabalhos realizados sobre o tema para esta área nos mais diversos objetivos, principalmente a relação da erosão com o uso do solo: PEREZ FILHO et al. (1986), SANTORO (1991), CARPI JUNIOR (1996), ALMEIDA FILHO et al. (2004), ZUQUETTE et al. (2007), GUIMARÃES (2008), MATHIAS (2011), DANIEL (2012) e DANIEL \& VIEIRA (2015). Tal área tem como substrato rochoso a Formação Piramboia do Grupo São Bento (Triássico - Jurássica) pertencente à Bacia Sedimentar do Paraná e inserida na Depressão Periférica Paulista, compartimento geomorfológico de origem denudacional, embutido entre áreas serranas elevadas e acidentadas (750 - $1600 \mathrm{~m})$ e as escarpas e festões das altas cuestas basálticas com altitudes entre $850 \mathrm{~m}$ - $1100 \mathrm{~m}$ (AB 'SABER 1949, SANCHEZ 1969, PINHEIRO et al. 2019).

Em relação às características pedológicas, predominam em grande parte da bacia Neossolo Quartzarênico com bandas onduladas (lamelas) e Neossolo Quartzarênico, Neossolo Litólico e Gleissolo, Neossolo Flúvico mais Gleissolo ao longo do canal principal, Latossolo vermelho na área circundante a montante do canal principal, fase arenosa, com espessura média de 15 a $20 \mathrm{~m}$, derivados de rochas básicas e mais argilosas (SANCHEZ 1971, SANTORO \& FULFARO 1996, FURQUIM 2002, VILLELA et al. 2018). 
A pluviosidade média anual varia entre 1200 a $1370 \mathrm{~mm}$, basicamente um período chuvoso nos primeiros e nos últimos meses do ano (verão), e um período mais seco (inverno) nos demais meses (SANTORO 1991), em que o total de chuvas do mês com menor índice pluviométrico não ultrapassa 30 mm (SILVA 1993). Ressaltam-se algumas anomalias pluviométricas exemplificadas pelo pico de chuva que ultrapassou $2200 \mathrm{~mm}$ no ano de 1983 e também registros menores que 1000 mm nos anos de 1960, 1963, 1968 e 1982 (CONTI 1971, CAPELLA et al. 2021).

As feições erosivas registradas (Figura 2) possuem área de $300 \mathrm{~m}^{2}$ até $48.000 \mathrm{~m}^{2}$, com profundida- de de $6 \mathrm{~m}$ até $21,50 \mathrm{~m}$, situadas no setor a montante, próximo a cabeceira do canal principal, constituída pela união de diversas ramificações. Tais feições também estão presentes na alta e média bacia, com maior densidade na margem direita do canal principal, com destaque para as voçorocas, localizadas em áreas circundantes de canais de primeira e segunda ordem, com ocorrência de processos subsuperficiais (registro de piping), sendo que a partir deste ponto no sentido à jusante, diminui significativamente o número de feições erosivas (DANIEL 2012, DANIEL \& VIEIRA 2015).

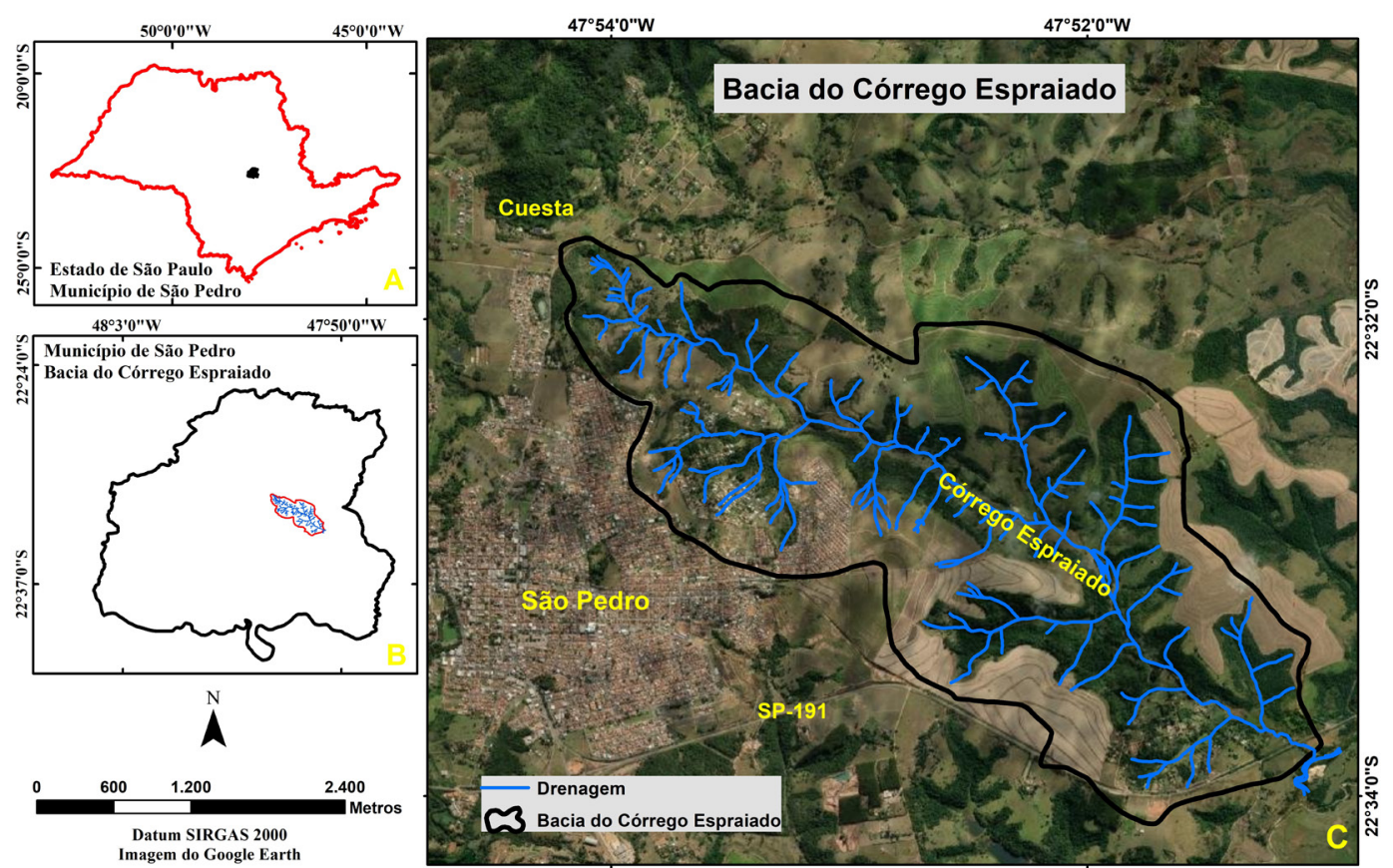

FIGURA 1 - Localização da área de estudo. (A) Estado de São Paulo. (B) A posição geográfica da bacia (em vermelho) na área territorial do município de São Pedro (SP) (em preto). (C) Detalhe da bacia em relação ao limite da cuesta, à área urbana de São Pedro (SP) e à rodovia SP-191. Fonte: Elaborada pelos autores.

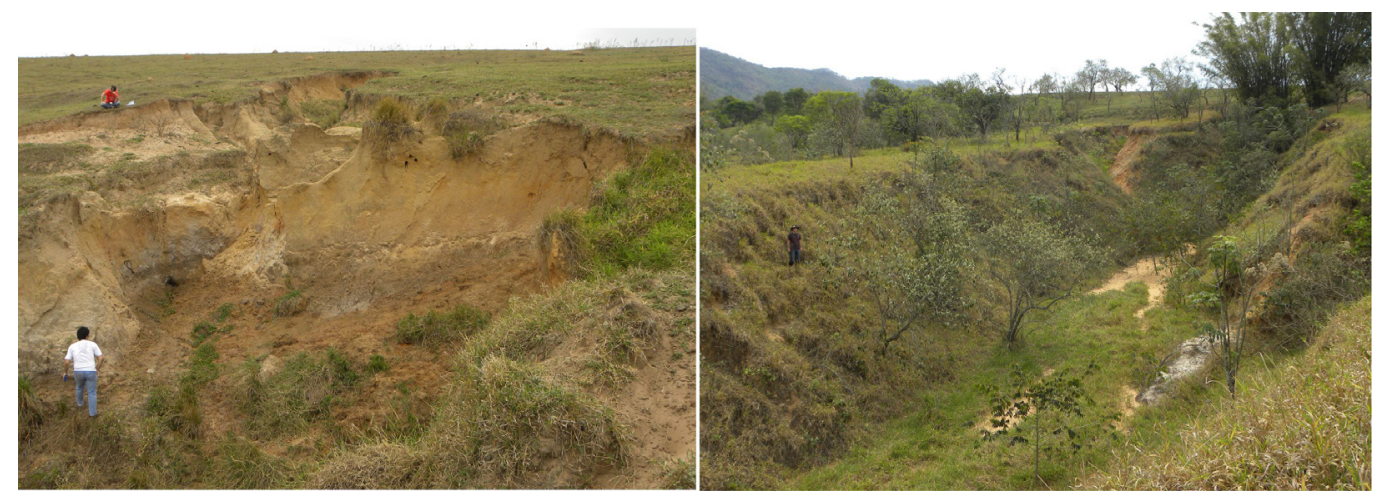

FIGURA 2 - Exemplos de feições erosivas na bacia do córrego Espraiado. Fotos dos autores. 


\section{MATERIAIS E MÉTODOS}

Os mapas do uso do solo e das feições erosivas foram realizados a partir de ortofotos referente aos respectivos cenários 1962 e 1972 (escala 1:25.000, Base S.A.), 2000 (escala 1:30.000, Base S.A.) e 2020, sendo que este último cenário foi atu- alizado por meio de trabalho de campo e por imagens do Google Earth.

A identificação das feições erosivas seguiu os seguintes critérios: sombreamento, solo exposto, entalhamento do relevo, fissuras no solo e declividade acentuada (Figuras 3 e 4). As classes de uso do solo foram identificadas e delimitadas conside-
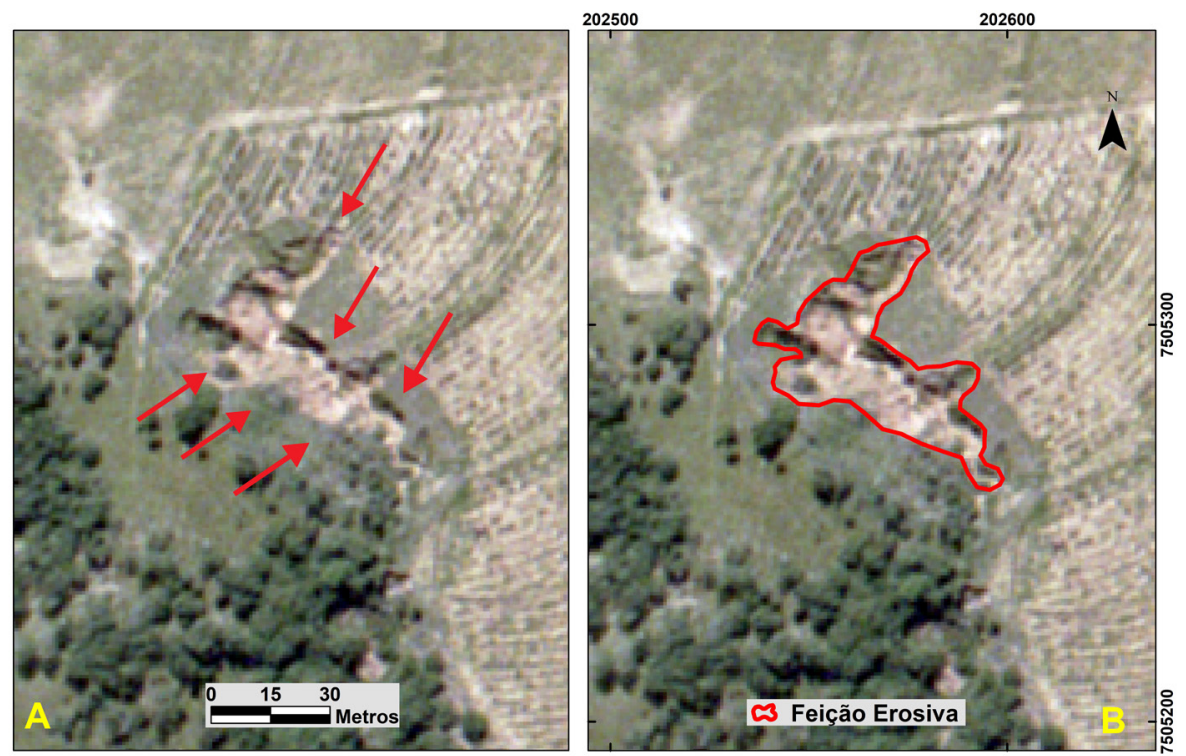

FIGURA 3 - Exemplo do mapeamento de feições erosivas. (A) Feição erosiva identificada na imagem. (B) Feição erosiva delimitada com o polígono em vermelho. Informações cartográficas: Datum: WGS 1984, Meridiano Central: $45^{\circ}$, Fuso UTM: 23K , Fonte das imagens: Base S.A. Elaborada pelos autores.
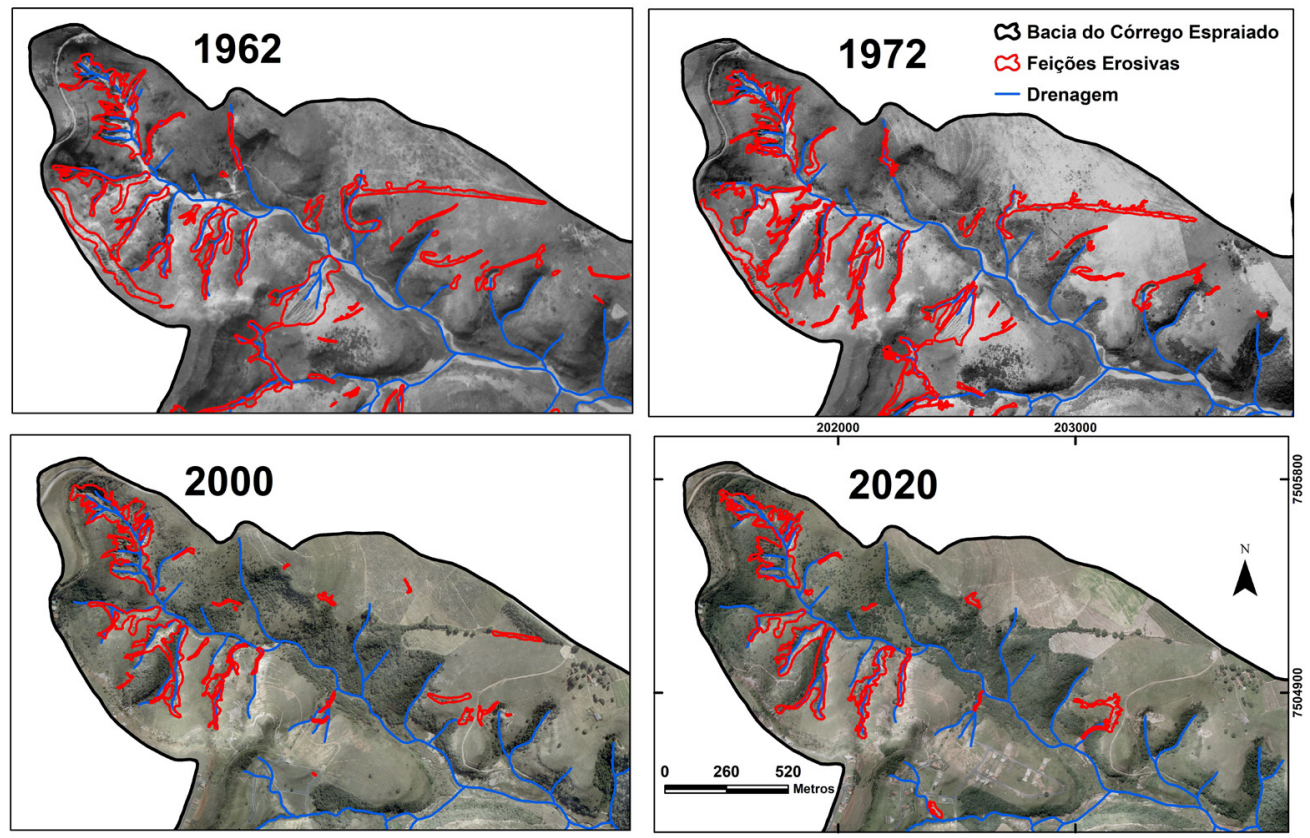

FIGURA 4 - Feições erosivas mapeadas no setor a montante da bacia em diferentes cenários (polígonos em vermelho). Informações cartográficas: Datum WGS 1984, Projeção UTM, Meridiano 45ㅇ, Fuso 23K, Fonte das imagens: 1962, 1972 e 2000 Base S.A; 2020 Google Earth. Elaborada pelos autores. 
rando alguns aspectos visuais tais como: cor, textura e arruamento, conforme proposto por ALMEIDA \& FREITAS (1996), a saber: áreas agrícolas, área urbana consolidada, área urbana inconsolidada, cobertura vegetal (mata), campos antrópicos/pastagens (modificado para pasto sujo e pasto limpo), sedimentos e vegetação em planície, silvicultura e solo exposto.

Os polígonos das classes de uso do solo (Figura 5) tiveram tonalidades atribuídas conforme IBGE (2006). Posteriormente, realizou-se o cálculo da área dos polígonos referentes às classes de uso do solo e das feições erosivas (Figura 6) de cada cenário, além de uma coluna na tabela de atributos dos polígonos para comparar ambos os mapas dos diversos cenários e caracterizar a dinâmica das classes e feições referente à área $\left(\mathrm{m}^{2}\right)$. Para complementar foi aplicado o índice de Potencial de Erosão (PE) a partir do método proposto por GAO (1993), que visa avaliar a correla- ção entre um elemento mapeado e sua ocorrência no interior de uma feição, ponderando a ocorrência de todo o elemento para toda a área; no caso em tela faz-se uma avaliação do elemento uso e ocupação apenas no interior do perímetro da feição erosiva, levando em conta a distribuição da classe de uso e ocupação para toda a bacia.

Em resumo, o índice de PE consiste na razão entre o número de células de cada classe afetada pelas feições erosivas e o total de células dessa mesma classe para toda a área, o que é executado a partir dos seguintes procedimentos: modificação do layer (formato shape) das feições erosivas para o mesmo formato que os mapas gerados pelo MDT (raster); seleção de células que há ocorrências de feições erosivas daquelas que não há ocorrência e por fim, geração de histogramas considerando apenas as classes que ocorrem no interior das feições, levando em conta a totalidade da classe para a bacia.
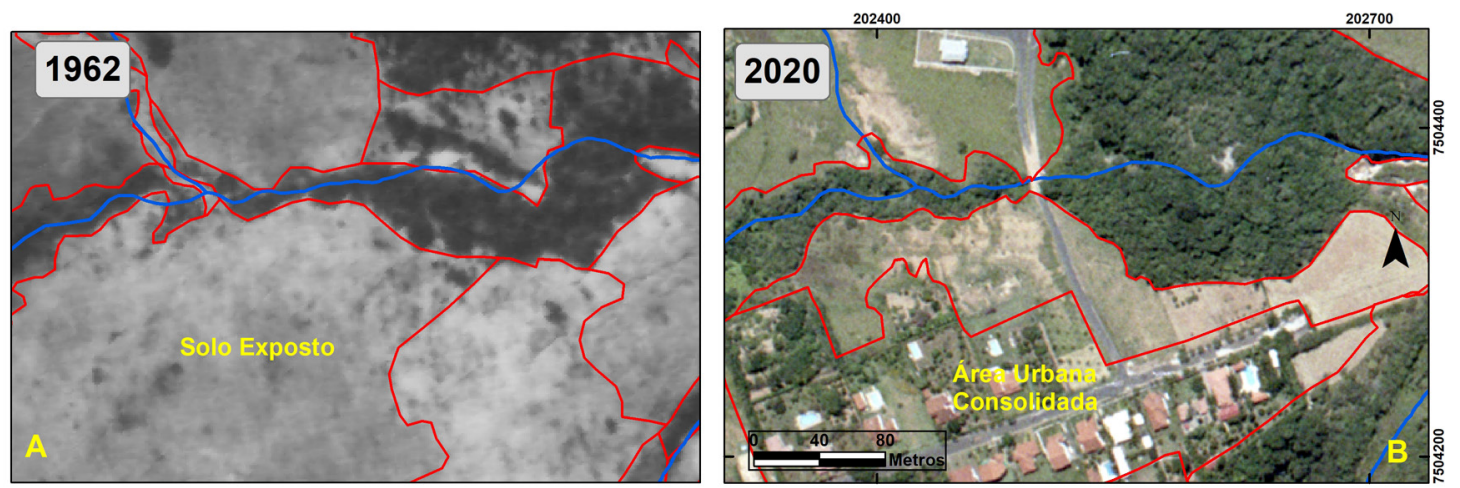

FIGURA 5 - Comparação da dinâmica do uso do solo. (A) Fragmento da ortofoto do cenário de 1962. (B) Fragmento da imagem Google Earth do cenário de 2020. Fonte: Elaborada pelos autores.
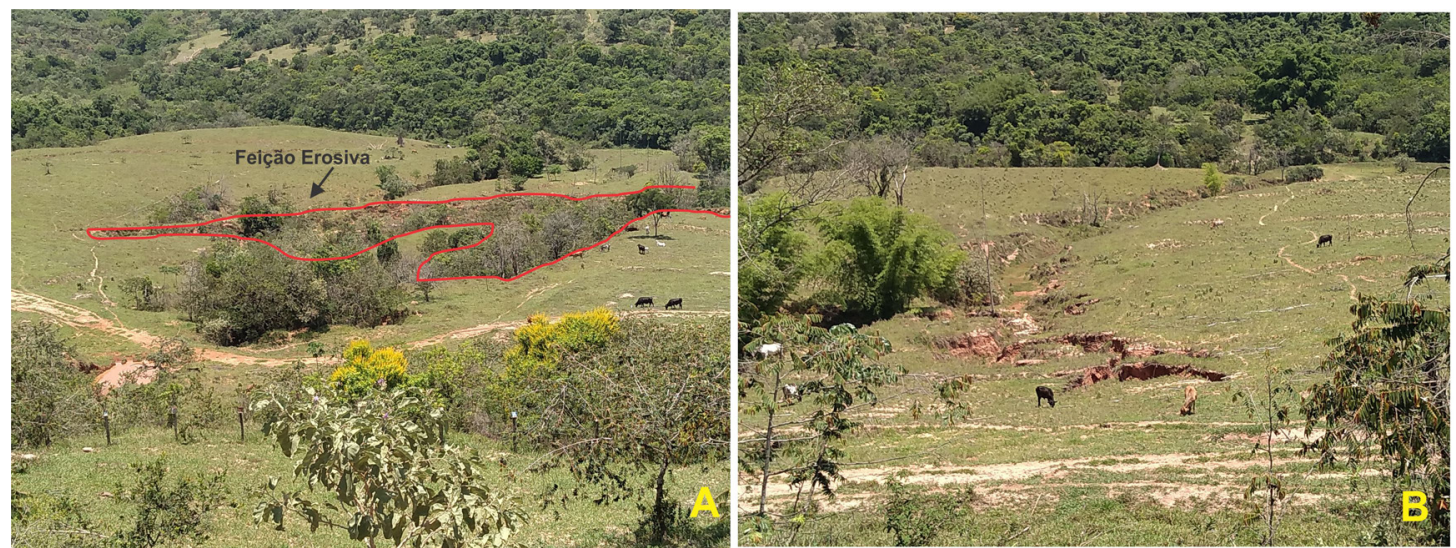

FIGURA 6 - (A) Registro (polígono vermelho) da feição erosiva intermediária (ravina) e a prática da pastagem ao seu entorno. (B) Registro da mesma feição erosiva na direção Norte-Sul e ao fundo o canal principal. Fonte: Fotos dos autores. 
Para fomentar tal discussão foram realizadas as cartas de declividade e de curvatura a partir do Modelo Digital de Terreno (MDT), elaborado por meio de um mosaico de cartas topográficas (Fazenda Araquá Mirim [SF-23 -Y-A-IV-I-NE-A]; Ribeirão da Grama [SF-23-Y-A-IV-I-NE-C]; São Pedro I [SF -23-Y-A-IV-NO-B] e São Pedro III [SF23-Y-A-IV-I-NO-D]), de escala 1:10.000, com curvas de nível equidistantes em $5 \mathrm{~m}$, elaboradas pela Terrafoto (Secretaria de Economia e Planejamento do Estado de São Paulo). Os intervalos foram considerados previamente, baseados em trabalhos sobre processos erosivos desenvolvidos por STABILE \& VIEIRA (2009) na região de Bauru (SP).

\section{RESULTADOS E DISCUSSÃO}

Nos cenários de 1962 e 1972 a classe de solo exposto apresentou a maior suscetibilidade, com PE entre 9,80\% (1962) e 11,60\% (1972) (Figuras 7 e 8). Na sequência, as classes mais suscetíveis nestes dois cenários foram pasto sujo e pasto limpo com valores de PE superiores a 3,0\%.
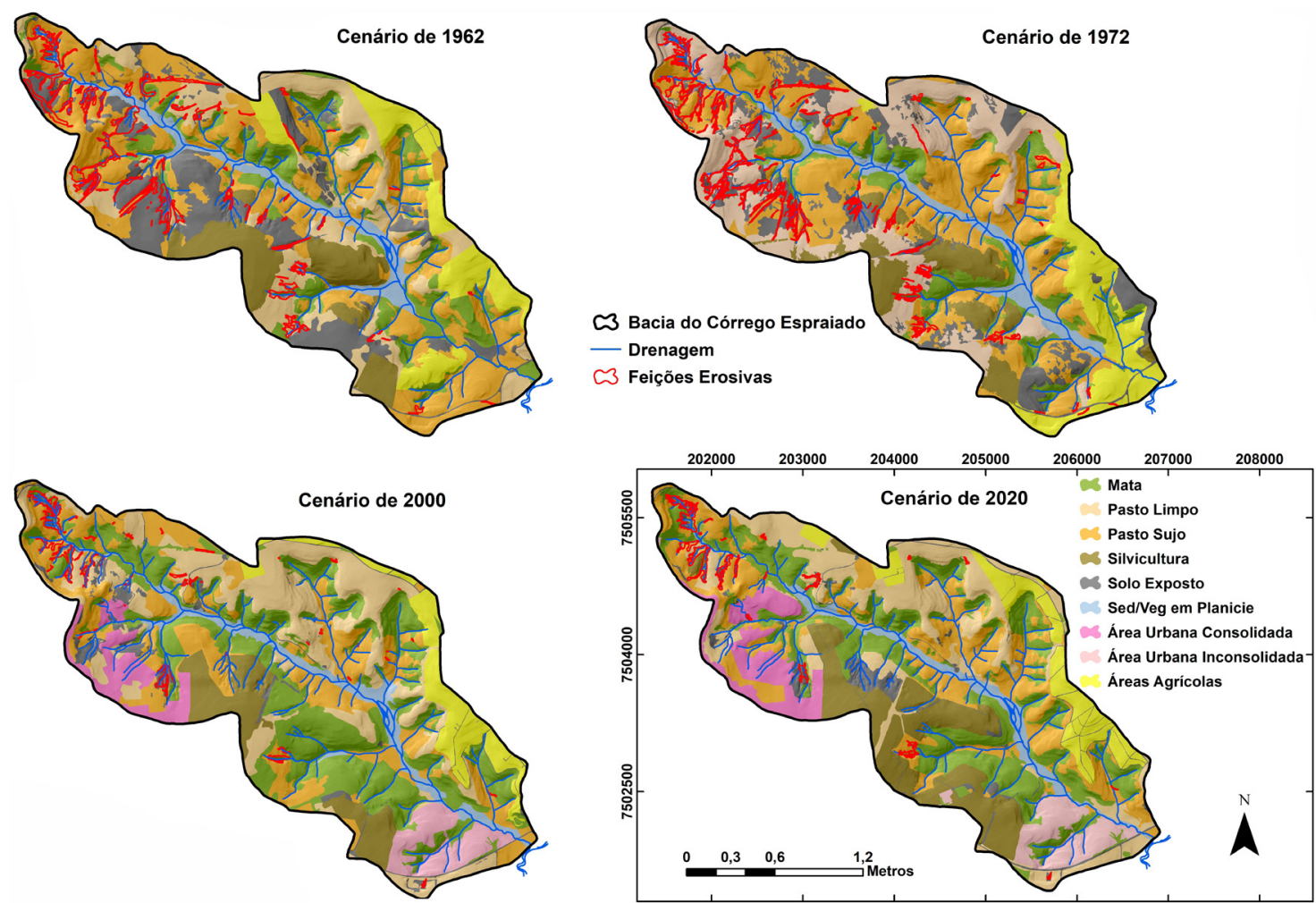

FIGURA 7 - Mapas de uso do solo e das feições erosivas nos cenários de 1962, 1972, 2000 e 2020. Informações cartográficas: Datum WGS 1984, Projeção UTM, Meridiano Central 45², Fuso 23K. Elaborada pelos autores.

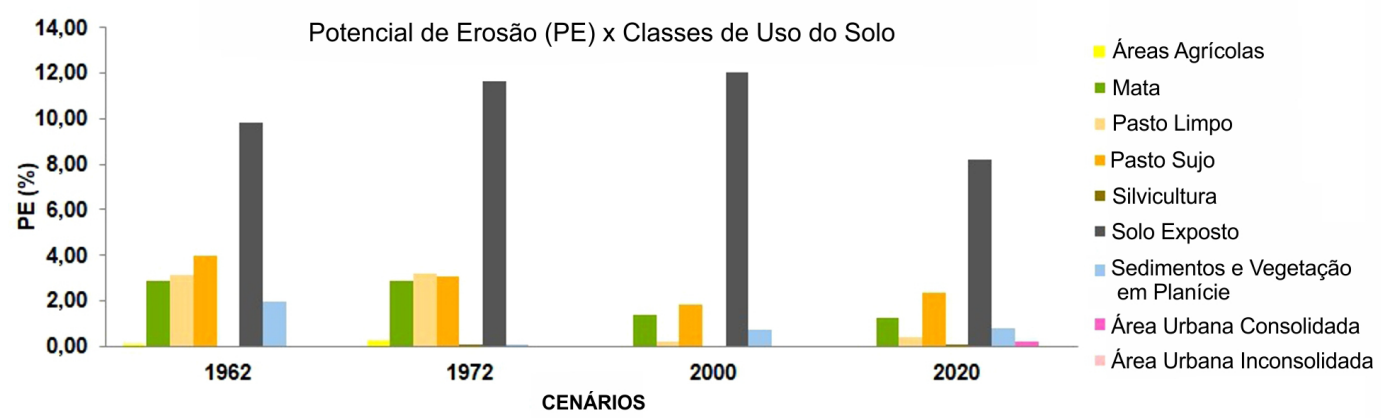

FIGURA 8 - Valores dos índices de PE de acordo com as classes de uso do solo em todos os cenários. 
Estas maiores suscetibilidades podem ser explicadas pela diminuição da porosidade devido ao manejo inadequado (compactação do solo) aliado a presença de Neossolos Litólicos e Gleissolos com baixa espessura (cerca de $60 \mathrm{~cm}$ ) e com menor capacidade de infiltração (FURQUIM 2002), respectivamente. Somam-se a estas características da paisagem, a média pluviométrica anual em torno de 1300 $\mathrm{mm}$, que podem aumentar o escoamento superficial.

Resultados similares foram observados por COUTARD et al. (1978), LOHMANN \& SANTOS (2005), VIEIRA (2006) e PINHEIRO (2008) que mostraram que a ativação dos processos erosivos está relacionada à associação entre a ocorrência de solos arenosos, o manejo inadequado do solo e o uso extensivo de pastagem (compactação do solo). LEMOS et al. (2011) analisaram feições erosivas numa sucessão histórica (1952, 1980 e 2001) no alto curso do rio Pitangui/PR e concluíram que suas formações estão associadas aos campos de pastagens ou pasto degradado e solo exposto.

CASTRO (2005) e SANTANA et al. (2007), por meio de mapeamento de feições erosivas e uso do solo, relataram que a porção jusante das encostas na alta bacia do rio Araguaia está sendo desmatada e substituída pela pastagem, gerando o desenvol- vimento das feições erosivas associadas à piping em áreas de Neossolo Quartzarênicos, dada a recarga rápida do lençol freático e o estabelecimento de fluxos efêmeros de alto poder erosivo, consequentemente a remoção de partículas.

A dinâmica do uso do solo dos cenários de 2000 e 2020 mostrou uma redução da área de pastagem (embora ainda predominante), o aumento das áreas de mata, o surgimento das áreas urbanas e a expansão da silvicultura. Entretanto, mesmo com estas alterações nas classes de uso, de acordo com Potencial de Erosão (PE), o solo exposto continuou sendo a classe mais suscetível ( $\mathrm{PE} \sim 12 \%$ ).

No cenário de 2000 ressalta-se o surgimento da classe de uso área urbana consolidada que, embora ocupe apenas $4 \%$ da área, contribuiu para a redução do número de feições erosivas iniciais (sulcos e ravinas) devido ao aterro e à implantação de loteamentos (Figuras 9 e 10). A expansão da silvicultura (plantio de eucaliptos) para fins econômicos nas áreas de Neossolos Quartzarênicos, Neossolos Litólicos e Gleissolos pode explicar em parte a redução das feições erosivas devido ao manejo com curvas de nível e terraceamento, contribuindo para a consequente diminuição do escoamento superficial. Entretanto,
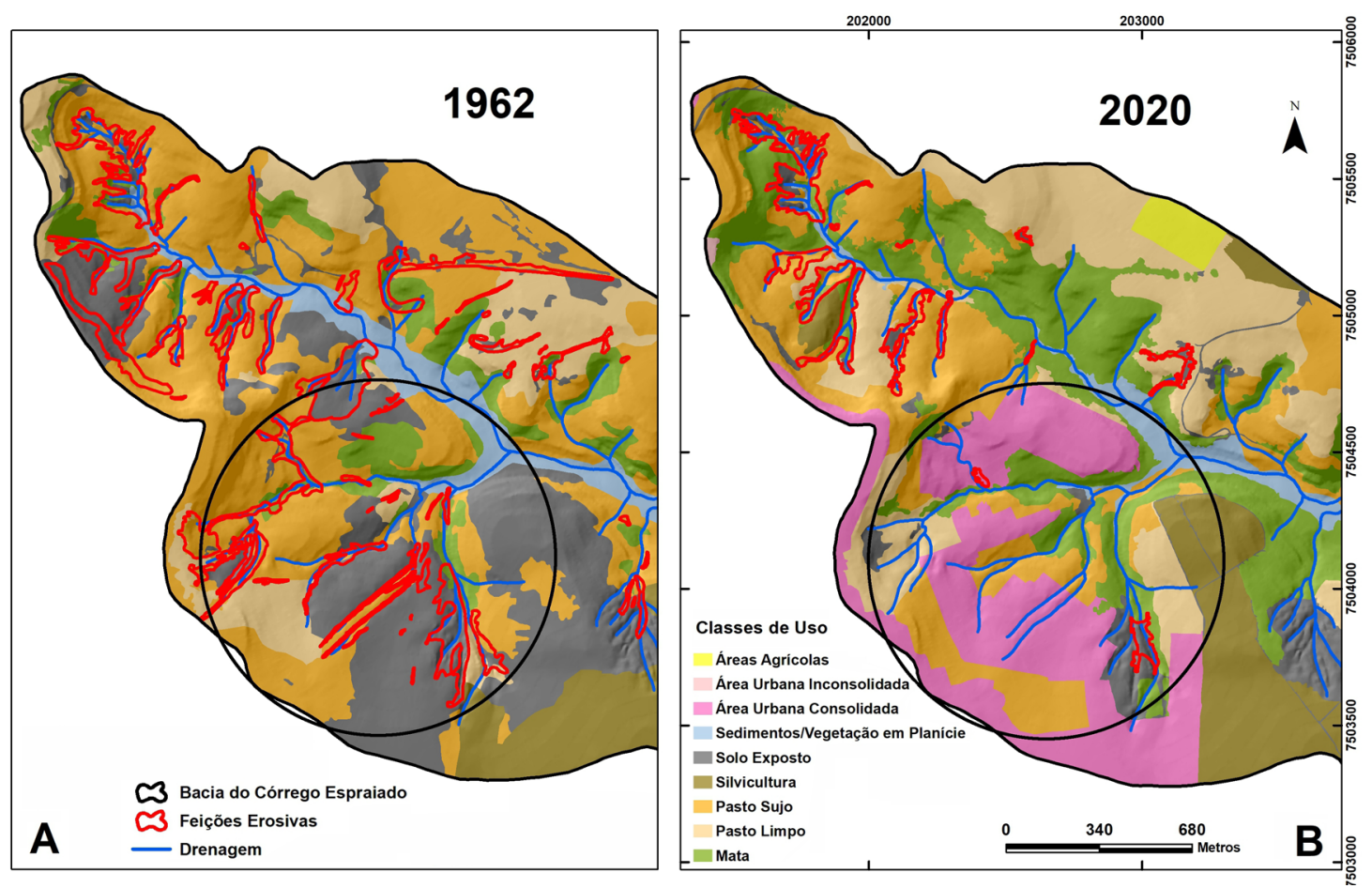

FIGURA 9 - (A) Cenário de 1962 destaca-se o uso com a pastagem e solo exposto (círculo em preto) e os polígonos de feições erosivas lineares. (B) Cenário de 2020 destaca-se a área urbana consolidada (círculo em preto), fragmentos de mata e pastagem e polígonos de feições erosivas lineares. Informações cartográficas: Datum WGS 1984, Projeção UTM, Meridiano Central 45, Fuso 23K. Elaborada pelos autores. 


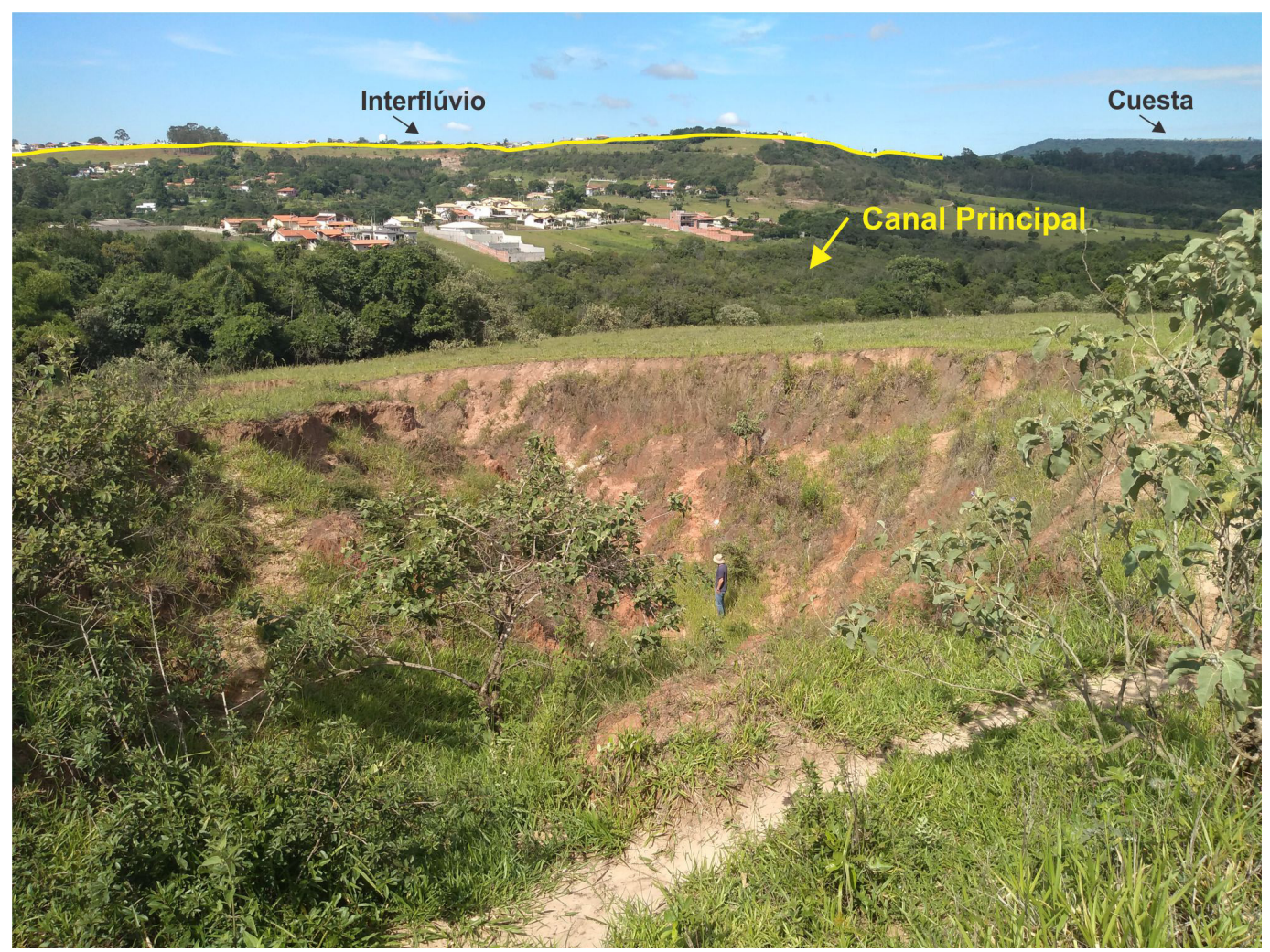

FIGURA 10 - Feição erosiva linear acelerada (voçoroca) em área periurbana. Foto dos autores.

PEREZ FILHO et al. (1986) relatam que o plantio de eucaliptos em Neossolos Quartzarênicos na bacia do córrego do Tucum em São Pedro (SP) não foi suficiente para conter os processos erosivos, mesmo sendo relativamente baixa a declividade (entre 8 e $10 \%$ ).

De acordo com YAMANOUTH (2003), os loteamentos implantados na bacia do córrego Espraiado têm relação direta com a reativação de feições de estágios avançados (voçorocas), uma vez que não há bacia de dissipação no término da canalização das águas superficiais, as barragens são feitas com o mesmo material inconsolidado (arenoso de granulação fina e média, espessura de até $3 \mathrm{~m}$ ) da área, além da falta de manutenção das obras realizadas. Neste contexto, SANCHEZ et al. (1986) afirmam que a implantação de loteamentos e o traçado do arruamento voltado para a encosta facilitou o escoamento das águas pluviais e servidas urbanas, porém dinamizou os processos erosivos.

Próximo à bacia do Espraiado, SANTORO (1991) realizou uma caracterização geotécnica e relatou que o desmatamento e a implantação de pastagens (compactação do solo e aumento do fluxo superficial) foram fatores desencadeadores e decisivos na aceleração de processos erosivos.
A maior suscetibilidade à erosão das classes de uso solo exposto e pastagem pode estar também associada à compactação do solo e à maior presença de curvaturas côncavas e das altas declividades (20$40 \%$ ) que, segundo DANIEL (2012) e DANIEL \& VIEIRA (2015), são as classes morfométricas mais suscetíveis da área (Figuras 11 e 12). Os mesmos autores explicam que elas estão situadas, sobretudo nas cabeceiras do canal principal, com predomínio de encostas abruptas, limitadas no topo pela presença de cornijas, vales encaixados e rupturas de declive. Neste estudo é justamente onde estão localizadas as classes de uso solo exposto e pastagem de maiores índices de PE em todos os cenários.

Outros estudos realizados na área corroboram os resultados encontrados nesta pesquisa. SANTORO \& FULFARO (1996), SILVA (2003) e YAMANOUTH (2003) afirmam que associação entre encostas mais declivosas (entre 10 - 40\%) e a presença de solos pouco espessos e francamente arenosos e porosos $(\sim 40 \%)$ facilitam a rápida saturação do solo e a remoção dos materiais inconsolidados por meio, sobretudo, do intenso escoamento superficial. 


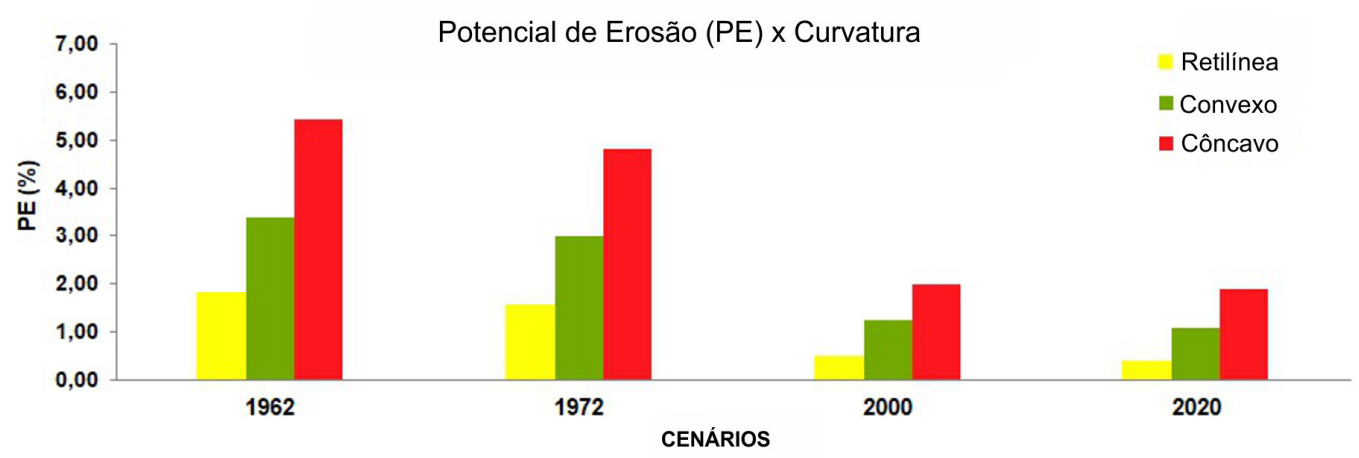

FIGURA 11 - Valores dos índices de PE de acordo com as classes de curvatura em todos os cenários.

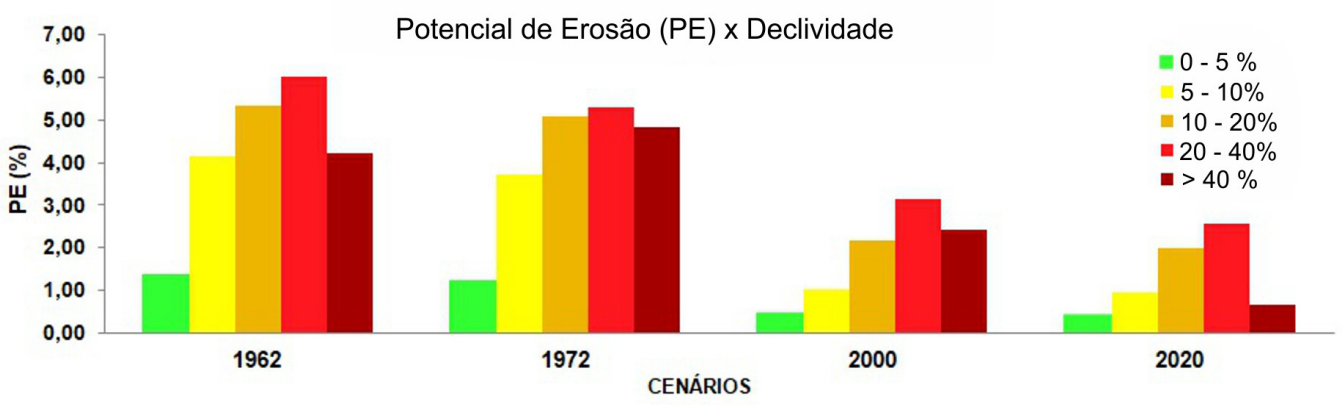

FIGURA 12 - Valores dos índices de PE de acordo com as classes de declividade em todos os cenários.

Em relação à curvatura das encostas, muitos estudos no Brasil (RODRIGUES 1982, OLIVEIRA \& MEIS 1985, CRUZ 2001, CASTRO 2005, LOHMANN \& SANTOS 2005, VIEIRA 2006, STABILE \& VIEIRA 2009, LEMOS et al. 2011)e também no mundo(TRIMBLE \& MENDEL 1995, SIDORCHUK 1999, CASASNOVAS 2003, MEYLES et al. 2006, GUTIÉRREZ et al. 2009, PHINZI \& NGETAR 2019) apontam as áreas de curvaturas côncavas como sendo mais favoráveis à erosão hídrica, sobretudo linear, devido à convergência de fluxos (KIRKBY \& CHORLEY 1967). Neste sentido, PINHEIRO (2009), na região de São Pedro (SP), identificou que as ravinas e voçorocas se instalaram preferencialmente em setores côncavos da encosta, em áreas de solos arenosos, profundos e homogêneos.

Entretanto, em trabalhos mais antigos, os autores também associam as erosões às encostas convexas (SANTORO 1991, SANTORO \& FULFARO 1996). Nesses casos, a presença de erosões em encostas convexas pode estar associada ao proces- so e técnica de aquisição dessas informações, pois os autores extraíram as classes de curvaturas de forma manual a partir das cartas topográficas, enquanto em pesquisas mais recentes este procedimento é realizado por meio de Modelos Digitais de Elevação com altas resoluções.

Para concluir é preciso salientar uma exceção em relação a esta tendência do aumento da declividade com o aumento da suscetibilidade, uma vez que o intervalo ( $>40 \%$ ) registrou uma redução do índice de PE 4,13\% a partir do cenário de 1972. Essa constatação pode estar relacionada à presença de solos poucos desenvolvidos nessas altas declividades, o que consequentemente reduz a probabilidade de ocorrência dessas feições. E, ainda, também pode estar relacionada com a menor intensidade das atividades antrópicas em tais setores, que neste caso é a pastagem, o que provavelmente aumenta a presença de cobertura de vegetação mais densa, pasto sujo, e consequentemente diminui a influência na distribuição e gênese das feições erosivas. 


\section{CONCLUSÕES}

A avaliação comparada por correlação cartográfica entre os mapas do uso do solo e das feições erosivas mostra que as classes de solo exposto e de pastagem (pasto sujo e pasto limpo) apresentam a maior suscetibilidade erosiva hídrica linear desde 1962.

Os mapas de uso do solo nos quatro cenários estudados (1962, 1972, 2000 e 2020), possibilitaram identificar a dinâmica da distribuição das classes e sua influência na concentração das feições erosivas, além de indicarem redução do número de feições erosivas a partir de 2000 quando se inicia o processo de urbanização na área e o aterro das mesmas, além da implantação de curvas de nível e terraceamento para o plantio da silvicultura, o que promoveu a diminuição do escoamento superficial.

A análise integrada também revelou que as áreas das cabeceiras de drenagens, com maior concentração de ocorrências erosivas em todos os cenários, estão associadas à presença expressiva da curvatura côncava, declividades entre 20 e $40 \%$ e classes de uso de solo exposto e classes de pastagens, além de marcadas, por um solo pouco espesso e pouco desenvolvido.

Tais conclusões corroboraram a literatura apresentada neste trabalho que tratam das relações entre os processos erosivos e o uso do solo.

\section{AGRADECIMENTOS}

Os autores agradecem o apoio financeiro do CNPq, por meio do Projeto 870227/19971. Processo 167550/2017-9 pela bolsa de estudo, como também a Prefeitura de São Pedro (SP) e proprietários das áreas rurais. Também expressam seu agradecimento aos revisores anônimos do periódico pelas críticas e sugestões.

\section{REFERÊNCIAS BIBLIOGRÁFICAS}

AB 'SABER, A.N. 1949. Regiões de circundesnudação pós-cretácea, no planalto brasileiro. Boletim de Geografia, 1: 3-21.

ALMEIDA, M.C.J.; FREITAS, C.G.L. 1996. O uso do solo urbano: suas relações com o meio físico e problemas decorrentes. In: ABGE, SIMPÓSIO BRASILEIRO DE CARTOGRAFIA GEOTÉCNICA, 2, São Carlos, Anais, p. 195-200.
ALMEIDA FILHO, G.S.; COSTA, S.B.; HELLMEISTER JUNIOR, Z.; CORSI, A.C. 2016. Situação da erosão hídrica linear no Estado de São Paulo, BR. In: ABGE, CONGRESSO DA SOCIEDADE DE ANÁlISE DE RISCO LATINOAMERICANA, 3, São Paulo, Anais, 7 p.

ALMEIDA FILHO, G.S.; SANTORO, J.; GOMES, L.A. 2004. Estudo da dinâmica evolutiva da boçoroca São Dimas no município de São Pedro, SP. In: GEDN/UFSC, SIMPÓSIO BRASILEIRO DE DESASTRES NATURAIS, 1, Florianópolis, Anais, p.73-86.

BORRELLI, P.; ROBINSON, D.A.; PANAGOS, P.; LUGATO, E.; YANG, J.E.; ALEWELL, C.; WUEPPER, D.; MONTANARELLA, L.; BALLABIO, C. 2020. Land use and climate change impacts on global soil erosion by water (2015-2070). Proceedings of the National Academy of Sciences of the United States of America, 117(36): 21994-22001. https://doi.org/10.1073/pnas.2001403117

CAPELLA, C.P.; VIEIRA, B.C.; DANIEL, E. 2021. Análise do papel da chuva na formação dos processos erosivos lineares em São Pedro (SP). In: UGB, SIMPÓSIO NACIONAL DE GEOMORFOLOGIA, 13, Juiz de Fora, no prelo.

CARPI JUNIOR, S. 1996. Técnicas cartográficas aplicadas à dinâmica da bacia do ribeirão Araquá (SP). Instituto de Geociências e Ciências Exatas, Universidade Estadual Paulista, Rio Claro, Dissertação de Mestrado em Organização do Espaço, 188 p.

CASASNOVAS, J.A.M. 2003. A spatial information technology approach for the mapping and quantification of gully erosion. Catena, 50(2-4): 293-308. https://doi. org/10.1016/S0341-8162(02)00134-0

CASTRO, S.S. 2005. Erosão hídrica na Alta Bacia do rio Araguaia: distribuição, condicionantes, origem e dinâmica atual. Revista do Departamento de Geografia, 17: 38-60. https:// doi.org/10.7154/RDG.2005.0017.0004

CONTI, J.B. 1971. Condições climáticas da região de Águas de São Pedro (SP). Caderno de Ciências da Terra, IGEOG-USP, 11: $15 \mathrm{p}$. 
COUTARD, J.P.; DIAS FERREIRA, R.P.; PELLERIN, J.; QUEIROZ NETO, J.P. 1978. Carta Geomorfológica de São Pedro (SP) - 1:50.000: Memorial Explicativo. Sedimentologia e Pedologia. Universidade de São Paulo.

CROSSON, P. 1995. Soil erosion estimates and costs. Science, 269(5223): 461-464. https:// doi.org/10.1126/science.269.5223.461

CRUZ, C. 2001. Análise comparativa da evoluçao das boçorocas nos anos de 1962 e 1999 nos municípios de Pompéia e Oriente (SP). Instituto de Geociências e Ciências Exatas, Universidade Estadual Paulista, Rio Claro, Dissertação de Mestrado, 105 p.

DANIEL, E. 2012. Análise do papel da morfologia e do uso do solo na gênese e na distribuição das feições erosvias na bacia do córrego Espraiado, São Pedro (SP). Faculdade de Filosofia, Letras e Ciências Humanas, Universidade de São Paulo, São Paulo, Dissertação de Mestrado, 183 p. https://doi.org/10.11606/D.8.2012.tde25022013-104558

DANIEL, E.; VIEIRA, B.C. 2015. A evolução das feições erosivas na bacia do córrego Espraiado, São Pedro (SP). Boletim Goiano de Geografia, 35(2): 339-358. https://doi. org/10.5216/bgg.v35i2.37435

FURQUIM, S.A.C. 2002. Interação entre modelado e solo no Transecto Espraiado, São Pedro (SP). Faculdade de Filosofia, Letras e Ciências Humanas, Universidade de São Paulo, São Paulo, Dissertação de Mestrado, 146 p. https://doi.org/10.11606/D.8.2002. tde-01082005-105035

GAO, J. 1993. Identification of topographic settings conducive to landsliding from dem in Nelson county, Virginia, U.S.A. Earth Surface Process and Landforms, 18: 579591. https://doi.org/10.1002/esp.3290180702

GOUDIE, A.S. 2004. Encyclopedia of Geomorphology. Routledge, London e New York, $1156 \mathrm{p}$.

GREENE, R.S.B.; HAIRSINE, P.B. 2004. Elementary processes of soil-water interaction and thresholds in soil surface dynamics: A review. Earth Surface Processes and Landforms, 29(9): 1077-1091. https:// doi.org/10.1002/esp.1103

GUIMARÃES, C.N. 2008. Mapeamento geotécnicoa da bacia da Barra, aplicação do penetrômetro em estudos de processos erosivos - São Pedro (SP) - Escala 1:10.000. Escola de Engenharia de São Carlos, Universidade de São Paulo, São Carlos, Dissertação de Mestrado. 104 p. https://doi.org/10.11606/D.18.2008. tde-23042008-093414

GUTIÉRREZ, Á.G.; SCHNABEL, S.; CONTADOR, F.L. 2009. Gully erosion, land use and topographical thresholds during the last 60 years in a small rangeland catchment in SW Spain. Land Degradation \& Development, 20(5): 535-550. https://doi. org/10.1002/ldr.931

IBGE, INSTITUTO BRASILEIRO DE GEOGRAFIA E ESTATÍSTICA. 2006. Manual técnico de uso da terra (2 ${ }^{\circ}$ Edição). Ministério do Planejamento, Orçamento e Gestão, Instituto Brasileiro de Geografia e Estatística - IBGE, Diretoria de Geociências. Coordenação de Recursos Naturais e Estudos Ambientais, $92 \mathrm{p}$.

KERTZMAN, F.F.; OLIVEIRA, A.M.; SALOMÃO, F.X.; GOUVEIRA, M.I.F. 1995. Mapa de erosão do estado de São Paulo. Revista do Instituto Geológico, 16 (número especial): 31-36. https://doi.org/10.5935/0100$-929 X .19950008$

KIRKBY, M.J.; CHORLEY, R.J. 1967. Throughflow, Overland Flow and Erosion. Bulletin of the International Association of Scientific Hydrology, 12(3): 5-21. https://doi. org/10.1080/02626666709493533

LEITE, C.H.; ORLANDO, P.H.K; VIOLA, M.R. 2016. Mapeamento de feições erosivas lineares em Tres Ranchos (GO). Espaço em Revista, 18(2): 100-110. https://doi.org/10.5216/ er.v18i2.40022

LEMOS, C.F.; FIORI, A.P.; OKA-FIORI, C.; TOMAZONI, J.C. 2011. Erosões concentradas existentes na Bacia Hidrográfica do Alto Curso do Rio Pitangui - PR Revista Brasileira de Geomorfologia, 12(1): 59-67. https://doi.org/10.20502/rbg.v12i1.219 
LOHMANN, M.; SANTOS, L.J.C. 2005. A morfopedologia aplicada à compreensão dos processos erosivos na Bacia Hidrográfica do arroio Guassupi, São Pedro do Sul - RS. Revista Brasileira de Geomorfologia, 6(2): 91102. https://doi.org/10.20502/rbg.v6i2.55

MATHIAS, D.T. 2011. Propostas de Recuperação de áreas peri-urbanas erodidas com base em parâmetros hidrológicos e geomorfológicos: córrego Tucunzinho - São Pedro (SP). Instituto de Geociências e Ciências Exatas, Universidade Estadual Paulista, Rio Claro, Dissertação de Mestrado, 128 p.

MEYLES, E.W.; WILLIAMS, A.G.; TERNAN, J.L.; ANDERSON, J.M.; DOWD, J.F. 2006. The influence of grazing on vegetation, soil properties and stream discharge in a small Dartmoor catchment, southwest England, UK. Earth Surface Processes and Landforms, 31(5): 622-631. https://doi.org/10.1002/ esp. 1352

MORGAN, R.P.C. 2005. Soil erosion and conservation. Blackwell Publishing On Line, Malden, $304 \mathrm{p}$.

NYSSEN， J.; POESEN， J.; MOEYERSONS, J.; LUYTEN, E.; VEYRET-PICOT, M.; DECKERS, J.; HAILE, M.; GOVERS, G. 2002. Impact of road building on gully erosion risk: A case study from the Northern Ethiopian Highlands. Earth Surface Processes and Landforms, 27(12): 12671283. https://doi.org/10.1002/esp.404

OLIVEIRA, M.A.T.; MEIS, M.R.M. 1985. Relações entre geometria do relevo e formas de erosão linear acelerada, Bananal (SP). Geociências, 4: 87-89.

PEREZ FILHO, A.; NOGUEIRA, F.P.; SANCHEZ, M.C.; TAVARES, A.C. 1986. Erosão acelerada em Areias Quartzosas no município de São Pedro. In: SBPC, ENCONTRO ANUAL DA SOCIEDADE BRASILEIRA PARA O PROGRESSO DA CIÊNCIA, 38, Curitiba, Anais, 24A: 12.

PHINZI, K.; NGETAR, N.S. 2019. Land use/ land cover dynamics and soil erosion in the Umzintlava catchment (T32E), Eastern Cape, South Africa. Transactions of the Royal Society of South Africa, 74(3):
223-237. https://doi.org/10.1080/003591 9X.2019.1634652

PINHEIRO, L.D.E.S. 2008. Análise da dinâmica plúvio-erosiva na bacia do córrego da Água Branca (SP). Instituto de Geociências e Ciências Exatas, Universidade Estadual Paulista, Rio Claro, Dissertação de Mestrado, 111 p.

PINHEIRO, M.R. 2009. Técnicas cartográficas e aerotogramétricas no estudo da erosão: alta bacia do ribeirão Araquá - São Pedro e Charqueada (SP). Faculdade de Filosofia, Letras e Ciências Humanas, Universidade de São Paulo, São Paulo, Dissertação de Mestrado, 219 p. https://doi.org/10.11606/D.8.2009.tde05022010-135011

PINHEIRO, M.R.; CIANFARRA, P.; VILLELA, F.N.J..; SALVINI, F. 2019. Tectonics of the Northeastern border of the Parana Basin (Southeastern Brazil) revealed by lineament domain analysis. Journal of South American Earth Sciences, 94: 102231. https://doi. org/10.1016/j.jsames.2019.102231

QUEIROZ NETO, J.P. 1978. Sistema de representação cartográfica empregados nas regiões do Paratei, São Pedro e Marília. Comunicação e Debates. Colóquio Interdisciplinar Franco-Brasileiro: Estudo e cartografia de formações superficiais e suas aplicações em regiões tropicais, 2: 23-37.

RODRIGUES, J.E. 1982. Estudos dos fenômenos erosivos acelerados: boçorocas. Escola de Engenharia de São Carlos, Universidade de São Paulo, São Carlos, Tese de Doutorado, $162 \mathrm{p}$.

SANCHEZ, M.C. 1969. Os municípios de São Pedro e Charqueada: aspectos de sua geografia agrária. Faculdade de Filosofia, Ciências e Letras, Universidade Estadual Paulista, Rio Claro, Tese de Doutorado, 135 p.

SANCHEZ, M.C. 1971. Contribuição ao conhecimento das bases naturais dos municípios de São Pedro e Charqueada (SP). Notícia Geomorfológica, 11(21): 47-60.

SANCHEZ, M.C.; MENDES, I.A.; FREITAS, M.I.C.; LORENZON FILHO, A.V. 1986. Monitoramento de forma de erosão acelerada no córrego Tucunzinho, no município de São 
Pedro (SP). Boletim de Geografia Teorética, 16-17: 276-284.

SANTANA, N.M.P.; CASTRO, S.S.; STONE, L.F.; SILVA, S.C. 2007. Chuvas, erosividade, erodibilidade, uso do solo e suas relações com focos erosivos lineares na alta bacia do rio Araguaia. Sociedade \& Natureza, 19(2): 103-121. https://doi.org/10.1590/s198245132007000200007

SANTORO, J. 1991. Fenômenos erosivos acelerados na região de São Pedro (SP): estudo da fenomenologia, com ênfase geotécnica. Instituto de Geociências e Ciências Exatas, Universidade Estadual Paulista, Rio Claro, Dissertação de Mestrado, 140 p.

SANTORO, J.; FULFARO, V.J. 1996. Estudos geotécnicos em boçoroca na cidade de São Pedro, São Paulo (SP). Revista do Instituto Geológico, 17(1/2): 55-62. http://dx.doi. org/10.5935/0100-929X.19960003

SIDORCHUK, A. 1999. Dynamic and static models of gully erosion. Catena, 37(3-4): 401-414. https://doi.org/10.1016/S03418162(99)00029-6

SILVA, A.F. 2003. Mapeamento geotécnico e análise dos processos erosivos na bacia do córrego Tucum, São Pedro (SP), Escala 1:10.000. Escola de Engenharia de São Carlos, Universidade de São Paulo, São Carlos, Dissertação de Mestrado, 131 p. https://doi.org/10.11606/D.18.2003.tde10042007-110730.

SILVA, L.C.F. 1993. Fotointerpretação de redes de drenagem e caracterização do relevo de dois solos do município de São Pedro (SP). Escola Superior de Agricultura "Luiz de Queiróz", Universidade de São Paulo, Piracicaba, Tese de Doutorado, 145 p. https:// doi.org/10.11606/T.11.2020.tde-20200111131801

STABILE, R.A.; VIEIRA, B.C. 2009. O papel do ângulo da encosta e da forma das vertentes na distribuição das feições erosivas da bacia Água da Faca, Piratininga (SP). In: UFV, Simpósio Brasileiro de Geografia Física Aplicada, 13, Viçosa (MG), Anais, 11 p.
THOMAZ，E.L.; FIDALSKI，J. 2020. Interrill erodibility of different sandy soils increases along a catena in the Caiuá Sandstone Formation. Revista Brasileira de Ciência do Solo, 44: 44:e0190064. https://doi.org/10.36 783/18069657rbcs20190064

TRIMBLE, S.W.; CROSSON, P. 2000. Land Use: U.S. Soil Erosion Rates-Myth and Reality. Science, 289(5477): 248-250. https://doi. org/10.1126/science.289.5477.248

TRIMBLE, S.W.T.; MENDEL, A.C. 1995. The cow as a geomorphic agent - a critical review. Geomorphology, 13: 233-253. https://doi. org/10.1016/0169-555X(95)00028-4

VIEIRA, W.C. 2006. Evolução de feições erosivas na microbacia do córrego Boa Vista, Prata $(M G)$. Instituto de Geografia, Universidade Federal de Uberlândia, Dissertação de Mestrado, Uberlândia, 132 p.

VILLELA, F.N.J; PINHEIRO, M.R.; QUEIROZ NETO, J.P.; MANFREDINI, S.; ALVES, G.B.; BARREIROS, A.M.; NAKASHIMA, M.R.; SCIGLIONO, B.F.; MICHELON, C.R.; DOS SANTOS, A.A.; SOARES, A.F.A.; BORSOI, H.R.G.; DE MELO, G.V.; SANTOS, F.R. 2018. Evolução do modelado de relevo e dos materiais no sopé da escarpa de cuesta de São Paulo (SP). Revista de Geografia (Recife), 35(4): 131-144.

WUEPPER, D.; BORRELLI, P.; FINGER, R. 2020. Countries and the global rate of soil erosion. Nature Sustainability, 3(1): 51-55. https://doi.org/10.1038/s41893-019-0438-4

YAMANOUTH, G.R.B. 2003. Avaliação dos processos erosivos e técnica de controle e reabilitação do córrego Espraiado (São Pedro/ $S P)$. Escola de Engenharia de São Carlos, Universidade de São Paulo, São Carlos, Dissertação de Mestrado, 211 p. https://doi. org/10.11606/D.18.2016.tde-11042016161906

ZUQUETTE, L.V.; CARVALHO, J.A.R.; YAMANOUTH, G.R.B. 2007. Feições erosivas na bacia do córrego do Espraiado, São Pedro (SP), seus tipos e evolução entre 1972-2002. Revista Brasileira de Geociências, 37(2): 414-425. 


\section{Endereço dos autores:}

Evandro Daniel e Bianca Carvalho Vieira - Universidade de São Paulo, Faculdade de Filosofia Letras e Ciências Humanas. Avenida Professor Lineu Prestes, Butantã, CEP: 05508-000, São Paulo, SP, Brasil. E-mails: evandrogeo@usp.br, biancacv@usp.br

Tiago Damas Martins - Universidade Federal de São Paulo, Instituto das Cidades. Avenida Jacú-Pêssego, 2630, Itaquera, CEP: 08260-001, São Paulo, SP, Brasil.E-mail: td.martins@unifesp.br

Artigo submetido em 2 de março de 2021, aceito em 12 de julho de 2021. 